\section{Temperatures in Heather Burning}

RECENTLY the subject of heather burning has come under more critical review. Of particular interest is the measurement of the temperatures recorded in fires and the effect of this heat on the establishment of new growth and the long-term effects on the fertility of the soil.

Whittaker ${ }^{1}$ recorded temperatures occurring in heather burning by means of 'Thermocolours', heat-sensitive paints, and in later experiments ${ }^{2}$, organic compounds of specific melting points. Her results show that the maximum temperatures experienced in heather burning are of the order of $840^{\circ} \mathrm{C}$ and that the temperatures most frequently recorded are between $300^{\circ} \mathrm{C}$ and $500^{\circ} \mathrm{C}$ at ground-level. It is suggested ${ }^{1}$ that these temperatures are maintained for periods of less than $2.5 \mathrm{~min}$.

The time-temperature complex, that is, the time during which fixed temperatures are maintained, is important from three different aspects. The regeneration of new growth both from seedlings and from the base of the old stem depends on this. In addition, work in this laboratory has shown that the losses of nitrogen in smoke depend on the period for which temperatures are maintained; and has demonstrated the varying solubility of nutrients in plant ash derived from heather leaves burnt under various temperature conditions.

Whittaker suggested the use of thermocouples as an accurate method for the measurement of fire temperatures. The major difficulty with this type of measurement is the recording of data under field conditions with no source of electricity to power bulky recorders and, amplifying systems. Mervyn Instruments, Ltd., have recently produced a portable transistorized recorder. This makes possible the recording of temperatures over any given range with the appropriate thermocouples.

Recordings were made over the range $0^{\circ}-1,000^{\circ} \mathrm{C}$. The recording equipment consisted of 5 thermocouple units connected to a manual switch, which in turn was connected to the recording instrument. Each thermocouple unit was made up from $3 \mathrm{ft}$. 'Insuglass Chromel Alumel' connected to compensating wire by copper points buried in the ground. The overall distance from the thermocouple point to the recorder was $40 \mathrm{ft}$.

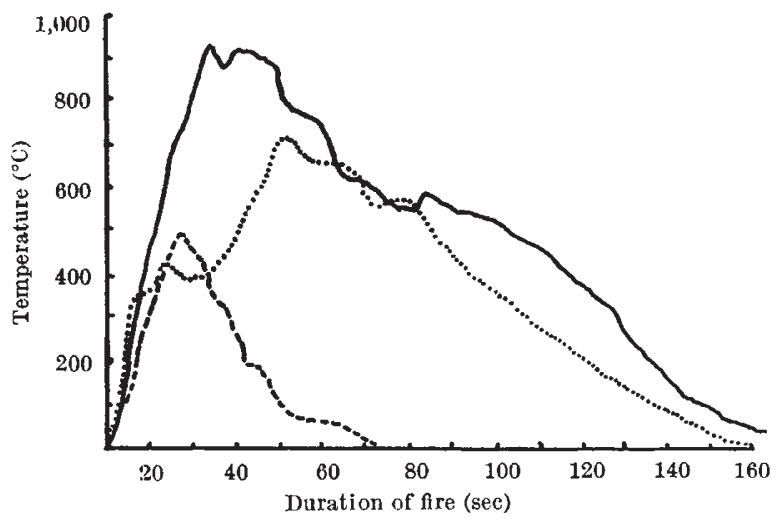

Fig. 1. Three chart records for vegetation of different ages. - $35 \mathrm{yr}$ old; $\cdots \cdots, 20$ yr. old; - - - , 10 yr. old

The results presented here are the result of work carried out in April 1963 on fires in Glen Clova, Angus. Fig. 1 shows the typical recording for heather of different ages, showing clearly the general increase in temperature of fires with increase in age of vegetation. All the readings are for temperatures recorded in the leafy parts of the plants. The maximum temperature recorded was $940^{\circ} \mathrm{C}$ and the average maximum from 35 fires was $670^{\circ} \mathrm{C}$. These temperatures are higher than those recorded by Whittaker ${ }^{1}$ under similar conditions. As the conditions last spring were particularly wet, it may well be that these

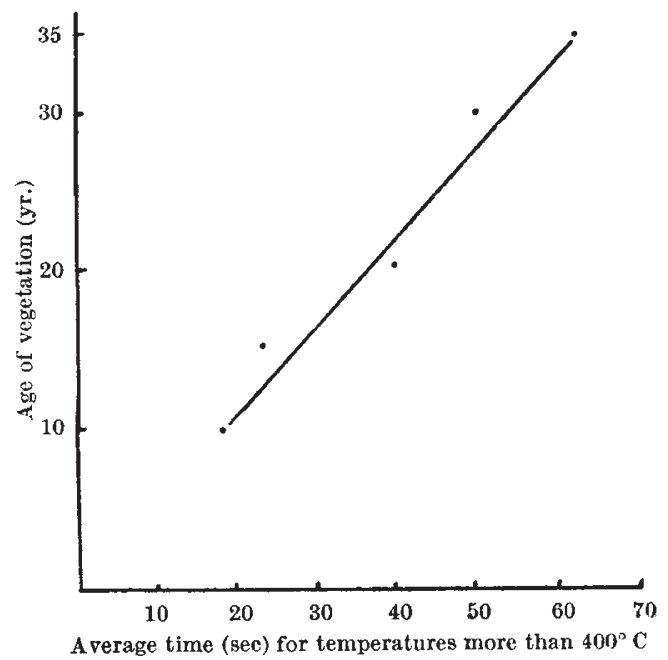

Fig. 2

temperatures may be exceeded when burning old heather.

At temperatures above $400^{\circ} \mathrm{C}$ there are significant losses of nitrogen in smoke, and thus it is important to estimate the time for which tempəratures more than $400^{\circ} \mathrm{C}$ are maintained. Fig. 2 shows the average time for which temperatures more than $400^{\circ} \mathrm{C}$ are maintained in the fires studied and its dependence on the age of the vegetation. Whittaker ${ }^{2}$ has used similar time periods for the study of heat tolerance of heather seeds. These results have confirmed Whittaker's predictions.

\section{J. B. KenworThy}

Department of Botany,

University of St. Andrews.

1 Whittaker, E., J. Ecol., 49, 709 (1961).

2 Whittaker, E., and Gimingham, C. H., J. Ecol., 50, 815 (1962).

\section{A Mould Inhibitor in Soybeans}

SeEDs of Glycine max Merr. (soybean) contain several biologically active materials, including saponins and trypsin inhibitors ${ }^{1}$. However, in a recent review of the antimicrobial activity of vascular plants ${ }^{2}$, no mention is made of the occurrence of antimicrobial compounds in soybeans. We are reporting the presence of a factor(s) that inhibits the mould growth of Rhizopus sp. (provisionally identified as $R$. oligosporus Saito), which is utilized in the fermentation of soybeans to make the Indonesian food tempeh ${ }^{3}$.

In making tempeh", soybeans are soaked in water for several hours, and then this water is discarded at the time the soybean hulls are removed. The dehulled beans are then boiled for $30 \mathrm{~min}$ in sufficient fresh water to cover the beans during the entire boiling process. This boiled water extract is discarded prior to inoculation and fermentation with Rhizopus. Under the fermentation conditions, the mould grows rapidly and in less than $24 \mathrm{~h}$ completely covers the soybeans. The soybeans are held together by the hyphæ of the mould and little sporulation occurs except at the edges of the moulded soybean mass if the fermentation is done in Petri dishes. In our investigations of tempeh, we found that an excellent product could be produced by using full-fat soybean grits. However, when the foregoing procedure of discarding the soaking and cooking water was used, it was discovered that considerable soybean material was discarded with the soaking and cooking water. For example, $1,200 \mathrm{~g}$ of dry, full-fat soybean grits were placed in beakers, covered with tap 